\title{
Correlation of Serum Copper and Zinc Levels with Glycemic Status in Patients with Newly Diagnosed Uncomplicated Type II Diabetes Mellitus
}

\author{
${ }^{1}$ Poonam Agarwal, ${ }^{2}$ Binita Goswami, ${ }^{3}$ Monica Verma, ${ }^{4}$ Sarika Arora, ${ }^{5}$ Bishamber D Tooraa
}

\begin{abstract}
Introduction: Diabetes mellitus (DM) is an epidemic facing the world today. The disease is characterized by a multitude of metabolic derangements which eventually lead to hyperglycemia and its associated complications. Trace elements, such as copper and zinc act as cofactors for essential enzymes of the metabolic pathways. Studies have reported conflicting results about their purported role in DM.
\end{abstract}

Materials and methods: The study was conducted on 22 newly diagnosed cases of type II DM (T2DM) and 30 age- and sexmatched healthy controls over a period of 2 months under the Indian Council of Medical Research Short Term Research Studentship (ICMR-STS) scheme. Blood glucose, serum zinc, copper, and glycated hemoglobin $(\mathrm{HbA} 1 \mathrm{c})$ levels were estimated using commercially available kits on Transasia XL 640. Data were collected and analyzed using appropriate statistical tests.

Results: The zinc levels were significantly decreased in the cases as compared with controls while there was no significant difference in the copper levels. A positive correlation between the copper and zinc levels was seen in the cases.

Conclusion: Trace elements play an important role in the maintenance of blood sugar levels and an in-depth understanding of the underlying pathways may help in a better management of DM.

Keywords: Copper, Glycated hemoglobin, Zinc.

How to cite this article: Agarwal P, Goswami B, Verma M, Arora S, Tooraa BD. Correlation of Serum Copper and Zinc Levels with Glycemic Status in Patients with Newly Diagnosed Uncomplicated Type II Diabetes Mellitus. Indian J Med Biochem 2018;22(1):32-35.

Source of support: The study was conducted under the ICMRSTS scheme.

Conflict of interest: None

1,2,4 Associate Professor, ${ }^{3}$ Student, ${ }^{5}$ Professor

1 Department of Biochemistry, Lady Hardinge Medical College \& Associated SSK\&KSC Hospitals, New Delhi, India

2,3,5Department of Biochemistry, Army College of Medical Sciences, New Delhi, India

${ }^{4}$ Department of Biochemistry, ESI Hospital, New Delhi, India

Corresponding Author: Binita Goswami, Associate Professor Department of Biochemistry, Lady Hardinge Medical College \& Associated SSK\&KSC Hospitals, New Delhi, India, Phone: +919810592004, e-mail: binita.dr@gmail.com

\section{INTRODUCTION}

Diabetes mellitus is a major health problem and is a disease of grave concern because of its rapidly increasing prevalence in the world. The International Diabetes Federation estimates a worldwide prevalence of 387 million $(8.3 \%)$ and the global burden of type II diabetes is expected to increase to 592 million by 2035. ${ }^{1,2}$ Once known as the "diabetes capital of the world," India was home to 61.3 million patients with T2DM in 2011 with predictions of 101.2 million diabetics by $2030{ }^{1,3}$ Presently, India is second only to China which is home to 92.3 million diabetics. This disease is of special concern in India due to its rapidly increasing prevalence. Recently, our research group has reported very high prevalence of diabetes in North India. ${ }^{4}$

Metabolic derangement due to altered regulation of enzymatic activity is the hallmark of T2DM. Minerals play a very important role in maintaining metabolic homeostasis through their diverse role. Copper and zinc act as cofactors for various enzymes maintaining the integrity of the metabolic pathway with a significant role in the maintenance of glucose homeostasis.

Copper is required for cytochrome oxidase activity, the loss of which seems to be associated with swelling and distortion of mitochondria of pancreatic acinar cell and some other metabolically active cells, such as enterocytes and hepatocytes. ${ }^{5}$ Various studies have demonstrated a deranged copper level in non-insulin dependent diabetes mellitus (NIDDM) with controversy regarding the actual role of copper with studies reporting conflicting results.

Zinc is an important trace element involved in synthesis, storage, and release of insulin. ${ }^{6}$ Hence, the assessment of serum level of zinc attains significant utility in NIDDM. Moreover, $\mathrm{Zn}$ and $\mathrm{Cu}$ antagonism is a well-studied phenomenon, making the assessment of zinc levels concurrently with copper levels an important aspect of our study to evaluate their interaction in patients of diabetes.

In a study done by Santa et $\mathrm{al}^{7}$ the serum $\mathrm{Cu}$ level was significantly elevated in uncomplicated T2DM patients as compared with healthy controls and it was positively correlated to fasting blood sugar (FBS). In another study conducted by Zargar et $\mathrm{al}_{1}^{8}$ the serum $\mathrm{Cu}$ level was significantly higher in NIDDM patients, but glycemic control 
as assessed by FBG and fructosamine levels was not influenced by serum copper levels. Schlienger et $\mathrm{al}^{9}$ have also assessed the role of copper levels in T2DM and have correlated its level with glycemic control. In their study also, copper level was found to be elevated in both IDDM and NIDDM, but glycemic control as assessed by HbA1c did not show any correlation with the copper levels.

Regarding the level of zinc in uncomplicated T2DM patients, Bozkurt et $\mathrm{al}^{10}$ found serum zinc to be higher as compared with healthy controls, though the difference was not found to be statistically significant $(p=0.336$ and $\mathrm{p}=0.498$ respectively). On the contrary, in a study done by Ferdousi et al, ${ }^{11} \mathrm{Zn}$ levels were found to be low in T2DM when the new cases were selected and analysis was done using atomic absorption spectrophotometer.

As controversy exists regarding the role of copper and zinc levels in NIDDM, more so when the disease duration is also taken into consideration, this case-control, observational study was designed to assess the levels of $\mathrm{Cu}$ and $\mathrm{Zn}$ and their correlation with FBS, and $\mathrm{HbA} 1 \mathrm{c}$ in new cases of diabetes.

\section{AIMS AND OBJECTIVES}

\section{Hypothesis}

This background leads to the proposed hypothesis that "Insulin resistance and hyperglycemic state of T2DM may be associated with the deranged profile of minerals like copper and zinc, and the degree of this derangement is correlated with the extent of hyperglycemia and $\mathrm{HbA} 1 \mathrm{c}$ levels."

\section{Aim}

To test this hypothesis, the serum level of $\mathrm{Cu}$ and $\mathrm{Zn}$ was assessed in newly diagnosed cases of T2DM and the serum level of these minerals was correlated with the disease state as specified by fasting plasma glucose (FPG) and HbA1c.

\section{MATERIALS AND METHODS}

This study was conducted at the Army College of Medical Sciences and Base Hospital, Delhi Cantonment, New Delhi, after getting clearance from the institutional ethical committee. It was an observational, prospective, case-control study done during a period of 2 months to assess the levels of $\mathrm{Cu}$ and $\mathrm{Zn}$ in relation to hyperglycemia and $\mathrm{HbA} 1 \mathrm{c}$ in new cases of uncomplicated T2DM. Twenty-two newly diagnosed patients of T2DM (group I) were recruited for the study after getting their informed written consent.

Newly diagnosed T2DM patients were those who were accidently diagnosed to have diabetes as characterized by $\mathrm{FPG} \geq 126 \mathrm{mg} / \mathrm{dL}$ and/or $\mathrm{HbA} 1 \mathrm{c} \geq 6.5 \%$ during their routine check-ups in the hospital. For the control group (group II), 30 age- and sex-matched apparently healthy volunteers were recruited. They were either the attender of the patients who accompanied the patients to the outpatient department or the volunteers from the Department of Biochemistry and Medicine. They were recruited for the study only after getting their informed written consent.

The following inclusion and exclusion criteria were used to select the study subjects.

\section{Inclusion Criteria}

- For group I patients having FPG $\geq 126 \mathrm{mg} / \mathrm{dL}$ and/ or $\mathrm{HbA} 1 \mathrm{c} \geq 6.5 \%$

\section{Exclusion Criteria}

- For all the groups, smokers, alcoholics, subjects with cancers, hypertension, renal and hepatic diseases, and any other acute/chronic illness; pregnant and postmenopausal ladies were excluded from the study to avoid any confounding effects.

- Person on laxatives, recent $\mathrm{h} / \mathrm{o}$ diarrhea and/or fluid infusion (within a week time) or persons taking vitamins and mineral supplement were also excluded.

\section{Biochemistry Measurements}

After obtaining informed and written consent, totally, $6 \mathrm{~mL}$ of fasting venous blood was collected by venipuncture using a flashback needle in the following vacutainers: $2 \mathrm{~mL}$ of blood in either of ethylenediaminetetraacetic acid (EDTA) vacutainer for $\mathrm{HbA} 1 \mathrm{c}$ estimation, in fluoride vacutainer for blood glucose estimation, and another $2 \mathrm{~mL}$ was transferred to plain vacutainer for the estimation of $\mathrm{Cu}$ and $\mathrm{Zn}$. Blood in EDTA and fluoride vacutainer was mixed properly and that in plain vacutainer was allowed to clot at $37^{\circ} \mathrm{C}$ for $20 \mathrm{~min}$. Plain vacutainers were centrifuged for $15 \mathrm{~min}$ at 3,000 rpm and aliquots of serum were prepared and stored at -20 degree centigrade to analyze $\mathrm{Cu}$ and $\mathrm{Zn}$ at a later date.

Fluoride vacutainers were centrifuged for $15 \mathrm{~min}$ at 3,000 rpm and plasma was separated from the fluoride vacutainer which was immediately analyzed for glucose. The $\mathrm{HbA1c}$ was also immediately estimated from the whole blood collected in an EDTA vacutainer.

\section{Method of Assessment of various Biochemical Profiles}

- The FPG levels were analyzed on Transasia XL-640, a fully automated system using glucose oxidaseperoxidase method ${ }^{12}$ 
- HbA1c was analyzed using Nycocard, an instrument based on ion exchange resin method.

- $\mathrm{Cu}$ and $\mathrm{Zn}$ were analyzed using semi-autoanalyzer Erba Chem 5 using colorimetric method. ${ }^{13-15}$

\section{Statistical Analysis}

All the data were statistically summarized with mean \pm standard deviation (SD). Differences in variables between groups were tested using a two-tailed, unpaired Student's t-test. Correlations were calculated to find out the relationship between variables in each group. Pearson's correlation coefficient $(\mathrm{r}$ ) was used to analyze correlation between different variables. All statistical analyses were performed by using Statistical Package for the Social Sciences version 17.0 for window program; $p$-values $<0.05$ were considered statistically significant. Statistical analysis was confirmed by consulting a qualified statistician and an expert opinion was obtained.

\section{OBSERVATION AND RESULT}

Various parameters of new cases of T2DM (group I) and control (group II) are compared in Table 1.

Pearson's correlation coefficient between various parameters is shown in Table 2.

Only significant correlation was found between $\mathrm{Cu}$ and $\mathrm{Zn}$ in group I where they show a positive correlation.

\section{DISCUSSION}

The role of minerals in the maintenance of health and its derangement in various diseases is a well-established fact. Diabetes is a state of deranged metabolism where various metabolic pathways, especially those of carbohydrate and lipid metabolism, are severely affected. The

Table 1: Mean \pm SD of $\mathrm{Cu}$ and $\mathrm{Zn}$ and glycemic status in groups I and II

\begin{tabular}{lllr}
\hline Parameters & $\begin{array}{l}\text { Group I (New } \\
\text { cases of T2DM) }\end{array}$ & $\begin{array}{l}\text { Group II } \\
\text { (Control) }\end{array}$ & p-value \\
\hline $\mathrm{Cu}(\mu \mathrm{g} / \mathrm{dL} \pm \mathrm{SD})$ & $100.07 \pm 9.44$ & $98.42 \pm 9.93$ & 0.547 \\
$\mathrm{Zn}(\mu \mathrm{g} / \mathrm{dL} \pm \mathrm{SD})$ & $66.95 \pm 7.08$ & $83.58 \pm 8.01$ & $<0.001$ \\
$\mathrm{FBS}(\mathrm{mg} / \mathrm{dL} \pm \mathrm{SD})$ & $145.14 \pm 18.61$ & $87.90 \pm 9.23$ & $<0.001$ \\
$\mathrm{HbA} 1 \mathrm{c}(\%)$ & $6.70 \pm 0.36$ & $5.72 \pm 0.48$ & $<0.001$ \\
\hline
\end{tabular}

Table 2: Pearson's correlation ( $r$ ) between various parameters in different study groups

\begin{tabular}{llc}
\hline Parameters & Group I (New cases) & Group II (Control) \\
\hline FBS vs Cu & 0.019 & 0.030 \\
FBS vs Zn & 0.024 & -0.278 \\
HbA1c vs Cu & 0.051 & 0.192 \\
HbA1c vs Zn & 0.124 & 0.102 \\
Cu vs Zn & $0.458^{*}$ & -0.163 \\
\hline
\end{tabular}

*Significant state of hyperglycemia in diabetes affects the mineral metabolism to a great extent. A number of studies have found deranged $\mathrm{Cu}$ and $\mathrm{Zn}$ level in T2DM.

Bozkurt et $\mathrm{al}^{10}$ and Ferdousi and $\mathrm{Mia}^{11}$ in their independent studies have shown a significant increase in the $\mathrm{Cu}$ level in new cases of T2DM. Zargar et al also have shown an increase in the serum copper level in T2DM when the mean duration of diabetes selected was $3.9 \pm$ 3.6 years. ${ }^{8}$ Contrary to the findings in the above studies, our study suggests that though the copper level shows a tendency toward increase in new cases of T2DM (group I) when compared with control population (group II), the difference in the $\mathrm{Cu}$ level is not statistically significant. Our finding is in coherence with the findings of Babalola et $\mathrm{al}^{16}$ where they also have failed to demonstrate any statistically significant difference in the level of copper in T2DM subjects when compared with controls.

Such controversial findings regarding the level of $\mathrm{Cu}$ in T2DM does not rule out the possibility of retention of copper in T2DM along with the progression of the disease. It is said so because while T2DM subjects in our study were new cases (group I), other studies where $\mathrm{Cu}$ is seen to be high had mixed population of T2DM subjects of different duration. Many of them have included even the cases who had diabetes for $>5$-year duration. Moreover, as the underlying complication of diabetes also affects the level of $\mathrm{Cu}$ in T2DM, due precaution is to be taken while selecting the subjects to rule out any underlying macro or micro vascular complication which may affect the copper level.

A number of studies done in the past have also shown altered levels of zinc in T2DM. Our study is showing significant lowering of zinc in newly diagnosed cases of T2DM as compared with controls. This finding is coherent with the finding of Ferdousi and $\mathrm{Mia}^{11}$ as they also found significant lowering of zinc and magnesium in newly diagnosed T2DM subjects. Walter et a ${ }^{17}$ have shown hyperzincuria in a 24-hour collection of urine in T2DM subjects and have shown a significant lowering of the $\mathrm{Zn}$ level in the serum of such patients, magnesium being normal.

Pearson correlation analysis shows a significant correlation in $\mathrm{Cu}$ and $\mathrm{Zn}$ only in group I patients, suggesting some interaction of these minerals at least during the initial phase of diabetes. On comparison of glycemia status in groups I and II, HbA1c was found to be higher in newly diagnosed T2DM compared with control group; this may be due to probable delay in the diagnosis of diabetes in group I patients.

Various contradictory findings regarding the level of serum copper in patients of T2DM mandate that the serum level of this mineral should be assessed in larger number of T2DM patients, and while selecting the study subjects, special consideration is to be given to the duration of 
diabetes. The level of copper should be regulated as an early therapeutic measure, as it is a well-known fact that an increase in the serum copper level may participate in the generation of free radicals through Fenton reaction, which in turn contributes to the increased oxidative stress of T2DM.

Zinc is also an important trace element critical for the functioning of various metalloproteins including members of oxidoreductase, hydrolase, ligase, lyase, and also function with $\mathrm{Cu}$ in the superoxide dismutase (SOD) activity. Maintaining the level of $\mathrm{Zn}$ via dietary supplementation certainly will benefit diabetic patients and will help in the regulation of metabolism and reduce the oxidative stress via strengthening the antioxidant role of SOD. One possibility of low zinc in the serum of T2DM in our study may be because of their loss through the urine of such patients. To find out this, 24-hour collection urine needs to be analyzed for excretion of $\mathrm{Zn}$.

\section{REFERENCES}

1. International Diabetes Federation. IDF diabetes atlas. In: IDF, eds. A Book. 6th ed. Brussels, Belgium: International Diabetes Federation; 2013.

2. Kaveeshwar SA, Cornwall J. The current state of diabetes mellitus in India. Australas Med J 2014;7(1):45-48.

3. Mohan V, Madan Z, Jha R, Deepa R, Pradeepa R. Diabetes social and economic perspectives in the new millennium. Int J Diab Dev Countries 2004;24:29-35.

4. Madaan H, Agrawal P, Garg R, Sachdeva A, Patra SK, Nair R. Prevalence of diabetes mellitus in rural population of district Sonepat, India. Int J Med Sci Pub Health 2014:3(3):261-264.

5. Aggett PJ. Physiology and metabolism of essential trace elements-an outline. In: Taylor A, ed. Clinics in endocrinology and metabolism. Philadelphia, PA: Saunders; 1985. pp. 513-543.
6. Roth HP, Kirchgessner M. Zinc and Insulin metabolism. Biol Trace Elem Res 1981 Mar;3(1):13-32.

7. Santa SR, Swati B, Choudhary Kanika M, Pal S, Aruna B, Gargi S. Status of serum magnesium, zinc \& copper in patients suffering from type 2 diabetes mellitus. J Drug Deliv Ther 2014,4(1),70-72.

8. Zargar AH, Shah NA, Masoodi SR, Laway BA, Dar FA, Khan AR, Sofi FA, Wani AL. Copper, zinc and magnesium levels in non-insulin dependent diabetes mellitus. Postgrad Med J 1998 Nov;74(877):665-668.

9. Schlienger JL, Grunenberger F, Maier EA, Simon C, Chabrier G, Leroy MI. Disorders of plasma trace elements in diabetes in relation to blood glucose equilibrium. Presse Med 1988 May;17(21):1076-1079.

10. Bozkurt F, Tekin R, Gulsun S, Satıc1 O, Deveci O, Hosoglu S. The levels of copper, zinc and magnesium in type II diabetic patients complicated with foot infections. Intern J Diabetes Dev Countries 2013 Sep;33(3):165-169.

11. Ferdousi S, Mia AR. Serum levels of copper and zinc in newly diagnosed type-2 diabetic subjects. Mymensingh Med J 2012 Jul;21(3):475-478.

12. Trinder P. Determination of glucose in blood using glucose oxidase with an alternative oxygen acceptor. Annals Clin Biochem 1969;6:24-27.

13. Abe A, Yamashita S, Nona A. Sensitive and direct colorimetric assay for copper in serum. Clin Chem 1989 Apr;35(4):552-554.

14. Saito M, Makino T. Estimation of zinc in serum by colorimetric assay. Clin Chim Acta 1998;120:127-135.

15. Bohuon C. Determination of magnesium levels in serum by colorimetric method. Clin Chim Acta 1962;7:811-817.

16. Babalola OO, Ojo LO, Akinleye O. Status of the levels of lead and selected trace elements in type 2 diabetes mellitus patients in Abeokuta, Nigeria. Afr J Biochem Res 2007 Dec;1(7):127-131.

17. Walter RM Jr, Uriu-Hare JY, Olin KL, Oster MH, Anawalt BD, Critchfield JW, Keen CL. Copper, zinc, manganese, and magnesium status and complications of diabetes mellitus. Diabetes Care 1991 Nov;14(11):1050-1056. 